\title{
Proliferation/quiescence: the controversial "aller-retour"
}

Bertrand Daignan-Fornier ${ }^{1,2}$ and Isabelle Sagot ${ }^{1,2^{*}}$

\begin{abstract}
The vast majority of cells, from prokaryotes up to vertebrate organisms, spend most of their time in quiescence, a state defined as a temporary and reversible absence of proliferation. Establishing the quiescent state while maintaining the capacity to re-enter the proliferation cycle are critical for cell survival and must be tightly orchestrated to avoid pathological proliferation. Hence, studying the biology of quiescent cells is an exciting research field. Taking advantage of technical progress in genomic, transcriptomic and metabolomic, the nature of transitions between proliferation and quiescence have been recently re-visited in budding yeast. Together with new findings in cell biology, these studies resuscitate an old demon in the field: the controversial existence of a "quiescence program".
\end{abstract}

\section{Introduction}

Quiescence is the most common cellular state on earth. While it is relatively easy to describe a proliferating cell, defining a quiescent cell is rather difficult. A commonly accepted, yet highly operational, definition of quiescence is "a reversible absence of proliferation". Consequently, a cell that is not dividing but eventually will when conditions become appropriate, is considered as a bona fide quiescent cell. But this definition is rather vague and probably encompasses various cellular situations. Therefore, instead of a single quiescent state, one can imagine that there may be distinct quiescent states depending on the cell's history before entry into quiescence, and/or depending on the time spent in quiescence (early quiescence, deep quiescence..., see Figure 1). This raises the delicate question of the existence of a quiescence "program". In other words, does quiescence result from a dedicated gene expression pattern that commits cells to the quiescent state or is quiescence an ultimate form of slow growth which would be a passive consequence of a cell's adaptation to unfavorable external conditions?

One major problem for studying quiescence comes from the fact that in multi-cellular organisms, environmental signals that control quiescence emanate from the entire organism - conditions that are difficult to reproduce in a

\footnotetext{
* Correspondence: isabelle.sagot@ibgc.cnrs.fr

'Institut de Biochimie et Génétique Cellulaires, Université Bordeaux, Bordeaux Cedex, France

Full list of author information is available at the end of the article
}

lab. By contrast, in single cell eukaryotes like budding yeast, quiescence entry and exit are solely conditioned by nutrient availability. Using this model, the nature of proliferation/quiescence transitions has recently been revisited.

\section{Discussion}

Quiescence entry: a diversity of adaptations

Budding yeast is THE model in which genetics has proven its power, and not surprisingly, using this organism, several genetic approaches have been developed in order to identify a dedicated mechanism that drives cells into quiescence. Many mutants were found to be specifically sensitive to one nutrient limitation [1-5], but only very few of them died upon all the starvation conditions tested $[1,2]$. At the present time, it is not known whether these mutants fail to enter, maintain or exit quiescence. Further, the genetic background of the yeast strain used for the screen, and in particular the auxotrophic markers, greatly influences the final result [1], thus complicating the interpretation of genetic approaches for the study of quiescence.

Global transcriptional analyses have demonstrated that gene expression patterns greatly vary depending on cell's history. In a very elegant study, Coller and co-workers, have clearly shown that in fibroblasts forced to enter quiescence by different routes, the gene expression profiles, while very different in the early days of quiescence, converge toward a common signature after several days spent in quiescence [6]. This raises the possibility of the 


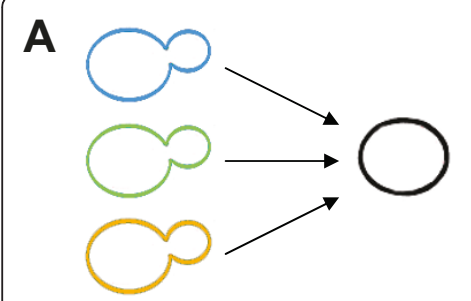

B

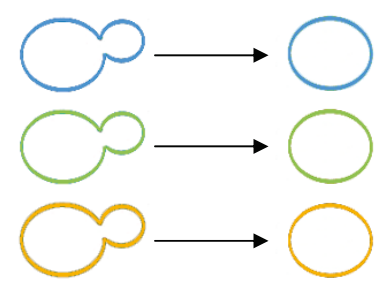

C

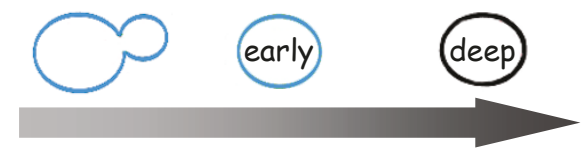

Figure 1 (A) Quiescence may be a unique cellular state that results from a dedicated program committing cells to quiescence. (B) Quiescence may vary depending on cell's history or (C) depending on the time spent in quiescence.

existence of different quiescent "states" depending on the time spent non-proliferating. It is not yet known whether early and deep quiescence notions are relevant in budding yeast. Nevertheless, in this organism it has clearly been shown that the overall mRNA profile was very different depending on the limiting nutrient. In fact, only a small set of genes are similarly regulated upon exhaustion of carbon, nitrogen, sulfur or phosphorus $[2,7,8]$. Therefore transcriptome data do not support the existence of a unique quiescent gene expression program that would commit yeast cells to the quiescent state. This assumption is further sustained by metabolomic studies revealing that none of the metabolic compounds measured showed a quiescence-specific behavior over all starvation conditions. Instead, the observed metabolic signatures were rather specific for the missing nutrient $[1,9]$. This strongly argues for the existence of different quiescent states depending on the history of the cell and reinforces the idea that quiescence might not be a committed state but rather an extreme manifestation of slow growth [1].

In fact, gene expression profiles of very slowly growing cells that are limited for one specific nutrient closely approximates the expression profile found in cells rendered quiescent by the total exhaustion of the same nutrient $[1,8,10]$. Moreover, it has been known for years that whatever the starvation conditions, quiescent cells acquire resistance to several stresses due to a modification of their cell wall [4]. Yet the same properties can be found in a population of extremely slow-growing cells in chemostat [1,11-14]. Additionally, upon carbon source exhaustion, a proportion of cells become denser [15], but again, this characteristic is apparently not specific of quiescent cells [16] and is probably due to the storage of specific carbohydrates that can occur in actively dividing cells during the oxidative phase of the metabolic cycle [17]. Finally, the idea of quiescence being an extreme form of slow growth is totally compatible with the fact that when nutrients are becoming scarce, or when protein synthesis is inhibited, the G1 phase of the cell cycle lengthens $[18,19]$. Therefore, the fact that in budding yeast, quiescence entry occurs preferentially in G1 could simply be the passive result of the metabolic slowdown.

\section{Quiescence entry: a commitment to a specific cellular} organization

As presented above, there are several pieces of evidence for quiescence entry being an adaptative transition to a paroxystic form of slow growth. However, other arguments, listed below, rather point to a real commitment to quiescence.

We have recently shown that while quiescence entry and G1 arrest are generally concomitant in budding yeast, an arrest in G1 is neither necessary nor sufficient for quiescence establishment [20]. Furthermore, quiescent cells and G1 arrested cells have very different transcription profiles $[5,21,22]$. Besides, when auxotrophic strains are starved for the metabolite they are unable to synthesize, cells do not uniformly arrest in G1, yet they face starvation by modifying their gene expression and metabolism [7]. Importantly this response is not sufficient for entering quiescence and these cells ultimately die massively [23]. Interestingly, cell death can be rescued by the inactivation of proteins that have been implicated in nutrient sensing and quiescence establishment (TOR, Sch9...) [23]. Therefore bona fide quiescence entry needs something more than a simple adaptative slow down of growth.

A puzzling observation made more than 30 years ago by Lillie and Pringle reports that yeast cells start to synthesize glycogen when half of the initial glucose is consumed, whatever the initial concentration [24]. Another striking feature is that upon carbon source exhaustion, the last division may not be an "ordinary division" since a significant proportion of bi-budded cells has been observed [25]. Consistently, quiescent cell populations contain more than the proportion of $50 \%$ daughter cells expected from regular division [15]. Therefore it seems that cells somehow actively anticipate the fact that they will soon be starved.

Additionally, we have shown that upon carbon starvation yeast assemble specific cellular structures: Actin Bodies and Proteasome Storage Granules (PSGs). These structures respectively result from the reorganization of the actin cytoskeleton and the re-localization of the proteasome from the nucleus to the cytoplasm $[26,27]$. These structures have never been observed in dividing cells, and, under specific conditions, can be assembled 
independently of G1 [20]. This indicates again that quiescence entry is not subjugated to cell cycle regulation. Importantly, in budding yeast, both Actin Bodies and PSGs do assemble upon abrupt transfer of dividing cells into water, a condition that is probably closer to what may happen in the wild. Furthermore, studies from the Marcotte and Werner-Washburne groups have shown that upon carbon source exhaustion, several proteins re-localize, a majority of them being metabolic enzymes [28-30]. Therefore, at the ultra-structural level, cells are committed to the quiescent state. Undoubtedly, a sole proliferation arrest, even in G1, is not enough to trigger Actin Body formation. Further, the utilization of cell cycle mutants has revealed that quiescence entry can be triggered several hours after the proliferation arrest by carbon source exhaustion [20]. Thus proliferation arrest and quiescence entry are not necessarily concomitant.

\section{Quiescence exit: a metabolic switch?}

Once committed to quiescence, cells need to survive and be able to maintain the capacity to re-proliferate. These two processes are poorly understood. Another layer of complexity is added by the fact that in budding yeast, mechanisms involved in transitions between quiescence and senescence or cell death are poorly understood. However, some light has recently been shed on the transition between quiescence and re-proliferation. Indeed, we found that a small proportion of cells can enter quiescence in another cell cycle phase than G1. Importantly, these cells can exit quiescence and give rise to progeny [20]. Therefore, like quiescence entry, quiescence exit is independent of G1.

Additionally, several studies have pointed to the fact that quiescent yeast cells seem to be somehow "prepared" to re-enter the proliferation state as fast as possible. Their transcription machinery is poised to specific gene promoters, ready to fire, and a burst of specific mRNA occurs in less than 5 minutes after nutrient addition [5,22]. Further, they make spatially arranged reserves that can be efficiently mobilized upon re-feeding. For example, actin is stored as Actin Bodies and long term polarity cues remain at one cell pole, both allowing to efficiently resume polarized cell growth $[31,32]$. Such a preparation strongly supports the idea of a quiescence program that "organizes" cells to be ready to proliferate as fast as possible upon nutrient replenishment.

Finally, the first committed step of quiescence exit does not require de novo protein synthesis. Indeed, structures found in quiescent cells can be readily mobilized upon nutrient re-feeding even in the presence of cycloheximide $[26,27,29]$. Consistently, the "mobilization signal" is rather metabolic and can be triggered by transferring quiescent cells into a glucose containing solution
$[20,33,34]$. In fact, we have shown that glucose has to be metabolized at least into pyruvate to trigger Actin Bodies mobilization [20]. This suggests that a small molecule, yet to be identified, may act either directly on quiescent cell structures, or via a cascade leading to a post-translational modification of a key protein that will in turn cause the mobilization of quiescent cells structures. Importantly, this "mobilization signal" is not sufficient to trigger cells re-proliferation. Therefore, like proliferation exit and quiescence entry, quiescence exit and re-entry into proliferation can be uncoupled, but such a decoupling ultimately leads to cell death [33].

\section{Conclusion}

In yeast, as in fibroblasts [6], a sole proliferation arrest is not sufficient to trigger quiescence entry and quiescent cells are more than just an ultimate form of slow growing G1 cells. Indeed, their commitment to a new cellular state is revealed by their re-organization at the ultra-structural level. Yet, recent evidence strongly supports the existence of various quiescent states depending on the cell's history. Therefore, quiescence could be the converging result of both an adaptive process allowing cells to cope with adversity and an active preparation to efficiently resume proliferation. Consequently the opposition between a quiescence-specific genetic program and an adaptation towards an ultimate form of slow growth might not be relevant. What is clear is that there is no need for subservience of quiescence entry and exit to cell cycle regulation. We rather propose that the metabolic status is a prevailing determinant for both quiescence entry and exit.

\section{Abbreviations}

PSG: Proteasome Storage Granules;

\section{Acknowledgements}

We thank J.P. Javerzat and D. McCusker for their comments on this manuscript. Our work is supported by the Université Bordeaux Segalen, the Conseil Regional d'Aquitaine, a Young Investigator grant from the Agence Nationale pour la Recherche (JC08 310804), a grant form Association pour la Recherche sur le Cancer (ARC; SFI20101201558) and a PEPS grant from the CNRS.

\section{Author details}

${ }^{1}$ Institut de Biochimie et Génétique Cellulaires, Université Bordeaux, Bordeaux Cedex, France. ${ }^{2}$ CNRS - UMR5095 Bordeaux, France.

Authors' contributions

I.S. and B.D.-F wrote the manuscript. The authors read and approved the final manuscript.

\section{Competing interests}

The authors declare that they have no competing interests.

Received: 21 April 2011 Accepted: 9 May 2011 Published: 9 May 2011

\section{References}

1. Gresham D, Boer VM, Caudy A, Ziv N, Brandt NJ, Storey JD, Botstein D: System-level analysis of genes and functions affecting survival during nutrient starvation in Saccharomyces cerevisiae. Genetics 2011, 187:299-317. 
2. Klosinska MM, Crutchfield CA, Bradley PH, Rabinowitz JD, Broach JR: Yeast cells can access distinct quiescent states. Genes Dev 2011, 25:336-349.

3. Aragon AD, Rodriguez AL, Meirelles O, Roy S, Davidson GS, Tapia PH, Allen C, Joe R, Benn D, Werner-Washburne M: Characterization of differentiated quiescent and nonquiescent cells in yeast stationaryphase cultures. Mol Biol Cell 2008, 19:1271-1280

4. Gray JV, Petsko GA, Johnston GC, Ringe D, Singer RA, Werner-Washburne M: "Sleeping beauty": quiescence in Saccharomyces cerevisiae. Microbiol Mol Biol Rev 2004, 68:187-206.

5. Martinez MJ, Roy S, Archuletta AB, Wentzell PD, Anna-Arriola SS, Rodriguez AL, Aragon AD, Quinones GA, Allen C, Werner-Washburne M: Genomic analysis of stationary-phase and exit in Saccharomyces cerevisiae: gene expression and identification of novel essential genes. Mol Biol Cell 2004, 15:5295-5305.

6. Coller HA, Sang L, Roberts JM: A new description of cellular quiescence. PLOS Biol 2006, 4:e83.

7. Saldanha AJ, Brauer MJ, Botstein D: Nutritional homeostasis in batch and steady-state culture of yeast. Mol Biol Cell 2004, 15:4089-4104.

8. Wu J, Zhang N, Hayes A, Panoutsopoulou K, Oliver SG: Global analysis of nutrient control of gene expression in Saccharomyces cerevisiae during growth and starvation. Proc Natl Acad Sci USA 2004, 101:3148-3153.

9. Boer VM, Crutchfield CA, Bradley PH, Botstein D, Rabinowitz JD: Growthlimiting Intracellular Metabolites in Yeast Growing Under Diverse Nutrient Limitations. Mol Biol Cell 2009, 21:198.

10. Brauer MJ, Huttenhower C, Airoldi EM, Rosenstein R, Matese JC, Gresham D, Boer VM, Troyanskaya OG, Botstein D: Coordination of growth rate, cell cycle, stress response, and metabolic activity in yeast. Mol Biol Cell 2008, 19:352-367.

11. Lindquist S, Kim G: Heat-shock protein 104 expression is sufficient for thermotolerance in yeast. Proc Natl Acad Sci USA 1996, 93:5301-5306.

12. Parsell DA, Lindquist $S$ : The function of heat-shock proteins in stress tolerance: degradation and reactivation of damaged proteins. Annu Rev Genet 1993, 27:437-496.

13. Piper P: Differential role of Hsps and trehalose in stress tolerance. Trends Microbiol 1998, 6:43-44.

14. Lu C, Brauer MJ, Botstein D: Slow growth induces heat-shock resistance in normal and respiratory-deficient yeast. Mol Biol Cell 2009, 20:891-903.

15. Allen C, Buttner $\mathrm{S}$, Aragon AD, Thomas JA, Meirelles $\mathrm{O}$, Jaetao JE, Benn $\mathrm{D}$, Ruby SW, Veenhuis M, Madeo F, Werner-Washburne M: Isolation of quiescent and nonquiescent cells from yeast stationary-phase cultures. J Cell Biol 2006, 174:89-100.

16. Benbadis L, Cot M, Rigoulet M, Francois J: Isolation of two cell populations from yeast during high-level alcoholic fermentation that resemble quiescent and nonquiescent cells from the stationary phase on glucose. FEMS Yeast Res 2009, 9:1172-1186.

17. Shi L, Sutter BM, Ye X, Tu BP: Trehalose is a key determinant of the quiescent metabolic state that fuels cell cycle progression upon return to growth. Mol Biol Cell 2010, 21:1982-1990.

18. Slater ML, Sharrow SO, Gart JJ: Cell cycle of Saccharomyces cerevisiae in populations growing at different rates. Proc Natl Acad Sci USA 1977, 74:3850-3854.

19. Johnston GC, Pringle JR, Hartwell LH: Coordination of growth with cell division in the yeast Saccharomyces cerevisiae. Exp Cell Res 1977, 105:79-98.

20. Laporte D, Lebaudy A, Sahin A, Pinson B, Ceschin J, Daignan-Fornier B, Sagot I: Metabolic status rather than cell cycle signals control quiescence entry and exit. J Cell Biol 2011, 192:949-957.

21. Gasch AP, Spellman PT, Kao CM, Carmel-Harel O, Eisen MB, Storz G, Botstein D, Brown PO: Genomic expression programs in the response of yeast cells to environmental changes. Mol Biol Cell 2000, 11:4241-4257.

22. Radonjic M, Andrau JC, Lijnzaad P, Kemmeren P, Kockelkorn TT, van Leenen D, van Berkum NL, Holstege FC: Genome-wide analyses reveal RNA polymerase II located upstream of genes poised for rapid response upon S. cerevisiae stationary phase exit. Mol Cell 2005, 18:171-183.

23. Boer VM, Amini S, Botstein D: Influence of genotype and nutrition on survival and metabolism of starving yeast. Proc Natl Acad Sci USA 2008, 105:6930-6935

24. Lillie SH, Pringle JR: Reserve carbohydrate metabolism in Saccharomyces cerevisiae: responses to nutrient limitation. J Bacteriol 1980, 143:1384-1394.
25. Sagot I, Schaeffer J, Daignan-Fornier B: Guanylic nucleotide starvation affects Saccharomyces cerevisiae mother-daughter separation and may be a signal for entry into quiescence. BMC Cell Biol 2005, 6:24.

26. Sagot I, Pinson B, Salin B, Daignan-Fornier B: Actin bodies in yeast quiescent cells: an immediately available actin reserve? Mol Biol Cell 2006, 17:4645-4655.

27. Laporte D, Salin B, Daignan-Fornier B, Sagot I: Reversible cytoplasmic localization of the proteasome in quiescent yeast cells. $J$ Cell Biol 2008, 181:737-745.

28. Tapia H, Morano KA: Hsp90 nuclear accumulation in quiescence is linked to chaperone function and spore development in yeast. Mol Biol Cell 2010, 21:63-72.

29. Narayanaswamy R, Levy M, Tsechansky M, Stovall GM, O'Connell JD, Mirrielees J, Ellington AD, Marcotte EM: Widespread reorganization of metabolic enzymes into reversible assemblies upon nutrient starvation. Proc Natl Acad Sci USA 2009, 106:10147-10152

30. Davidson GS, Joe RM, Roy S, Meirelles O, Allen CP, Wilson MR, Tapia PH, Manzanilla EE, Dodson AE, Chakraborty S, et al: The proteomics of quiescent and nonquiescent cell differentiation in yeast stationary-phase cultures. Mol Biol Cell 2011, 22:988-998.

31. Chant J, Pringle JR: Patterns of bud-site selection in the yeast Saccharomyces cerevisiae. J Cell Biol 1995, 129:751-765.

32. Sahin A, Daignan-Fornier B, Sagot I: Polarized growth in the absence of Factin in Saccharomyces cerevisiae exiting quiescence. PLoS One 2008, 3: e2556.

33. Granot D, Snyder M: Glucose induces CAMP-independent growth-related changes in stationary-phase cells of Saccharomyces cerevisiae. Proc Natl Acad Sci USA 1991, 88:5724-5728.

34. Granot D, Snyder M: Carbon source induces growth of stationary phase yeast cells, independent of carbon source metabolism. Yeast 1993, 9:465-479.

doi:10.1186/1747-1028-6-10

Cite this article as: Daignan-Fornier and Sagot: Proliferation/quiescence: the controversial "aller-retour". Cell Division 2011 6:10.

\section{Submit your next manuscript to BioMed Central and take full advantage of:}

- Convenient online submission

- Thorough peer review

- No space constraints or color figure charges

- Immediate publication on acceptance

- Inclusion in PubMed, CAS, Scopus and Google Scholar

- Research which is freely available for redistribution 